See discussions, stats, and author profiles for this publication at: https://www.researchgate.net/publication/284546043

\title{
Controlled release of drugs from cellulose acetate matrices produced from sugarcane bagasse: Monitoring by square-wave voltammetry
}

Article in Drug Development and Industrial Pharmacy · November 2015

DOI: $10.3109 / 03639045.2015 .1107093$

\section{CITATION}

7 authors, including:

\section{Sabrina Ribeiro}

Universidade Federal de Uberlândia (UFU)

8 PUBLICATIONS 62 CITATIONS

SEE PROFILE

(2.) Rosana Assunção

Universidade Federal de Uberlândia (UFU)

62 PUBLICATIONS 1,083 CITATIONS

SEE PROFILE

Some of the authors of this publication are also working on these related projects:

working with biofuels, green chemistry and synthesis organic. View project

Elelectroanalytical methods and sensors View project
Rodrigo A. A. Munoz

Universidade Federal de Uberlândia (UFU)

178 PUBLICATIONS 2,510 CITATIONS

SEE PROFILE

Hernane Da Silva Barud

Centro Universitário de Araraquara

123 PUBLICATIONS 1,990 CITATIONS

SEE PROFILE 


\section{Controlled release of drugs from cellulose acetate matrices produced from sugarcane bagasse: monitoring by square-wave voltammetry}

\section{Guimes Rodrigues Filho, Flávia Almeida, Sabrina D. Ribeiro, Thiago F. Tormin,} Rodrigo A. A. Muñoz, Rosana M. N. Assunção \& Hernane Barud

To cite this article: Guimes Rodrigues Filho, Flávia Almeida, Sabrina D. Ribeiro, Thiago F. Tormin, Rodrigo A. A. Muñoz, Rosana M. N. Assunção \& Hernane Barud (2015): Controlled release of drugs from cellulose acetate matrices produced from sugarcane bagasse: monitoring by square-wave voltammetry, Drug Development and Industrial Pharmacy, DOI: 10.3109/03639045.2015.1107093

To link to this article: http://dx.doi.org/10.3109/03639045.2015.1107093

Published online: 23 Nov 2015.

Submit your article to this journal $[\pi$

Q View related articles ¿

View Crossmark data $₫$ 


\title{
Controlled release of drugs from cellulose acetate matrices produced from sugarcane bagasse: monitoring by square-wave voltammetry
}

\author{
Guimes Rodrigues Filho ${ }^{a}$, Flávia Almeida ${ }^{a}$, Sabrina D. Ribeiro ${ }^{a}$, Thiago F. Tormin ${ }^{a}$, Rodrigo A. A. Muñoz ${ }^{a}$, Rosana M. \\ N. Assunção ${ }^{b}$ and Hernane Barud ${ }^{c}$ \\ anstituto De Química, Universidade Federal De Uberlândia, Uberlândia, Minas Gerais, Brazil; ${ }^{\mathrm{b}}$ Faculdade De Ciências Integradas Do Pontal, \\ Universidade Federal De Uberlândia, Ituiutaba, Minas Gerais, Brazil; 'Instituto De Química, Universidade Estadual Paulista "Júlio De Mesquita Filho", \\ Rua Francisco Degni, 55, Quitandinha, Araraquara - SP, Brazil
}

ABSTRACT

In this paper, cellulose triacetate (CTA) was produced from sugarcane bagasse and used as matrices for controlled release of paracetamol. Symmetric and asymmetric membranes were obtained by formulations of CTA/dichloromethane/drug and CTA/dichloromethane/water/drug, respectively, and they were characterized by scanning electron microscopy (SEM) and differential scanning calorimetry (DSC). Different morphologies of membranes were observed by SEM, and the incorporation of paracetamol was confirmed by lowering of the glass transition temperature $\left(T_{\mathrm{g}}\right)$ in the DSC curves. This indicates the existence of interactions between the matrix and the drug. The evaluation of drug release was based on the electrochemical monitoring of paracetamol through its oxidation at a glassy carbon electrode surface using square-wave voltammetry (SWV), which provides fast, precise and accurate in situ measurements. The studies showed a content release of $27 \%$ and $45 \%$ by the symmetric and asymmetric membranes, respectively, during $8 \mathrm{~h}$.
ARTICLE HISTORY

Received 24 June 2015

Revised 3 September 2015

Accepted 5 October 2015

Published online

24 November 2015

\section{KEYWORDS}

Cellulose acetate, controlled release, membranes, square wave voltammetry, sugarcane bagasse

\section{Introduction}

Controlled release systems are, ideally, devices that disseminate an active agent when and where it is required at a level of concentration sufficient to generate the expected effect ${ }^{1}$. Controlled release systems are designed to prolong the release time of the drug in the organism, to sustain its plasma concentration and to control the temporal and spatial location of molecules in vivo through biological and chemical principles. In this way, cyclical changes in the concentration are eliminated and the bioavailability of the drug is increased. Furthermore, drug toxicity can be reduced, and controlled release systems can suppress adverse reactions, decrease the number of doses administered, increase the safety of drugs and can increase the plasma concentration of active principles with a short half-life ${ }^{1}$.

The improvement in the development of controlled release systems depends on the selection of an appropriate agent that is capable of controlling drug release, maintaining the therapeutic action over time and/or releasing the drug at a specific target tissue or organ. Given the various options, polymers are versatile and promising agents to perform such functions ${ }^{2}$. Cellulose acetate is one of the components used in systems for controlled release of drugs and are used in the form of membranes ${ }^{3-19}$.

In previous work ${ }^{6}$, symmetric and asymmetric membranes of cellulose triacetate, produced from sugarcane bagasse were used as matrices for the controlled release of drugs. The drug incorporated was doxycycline and the release was evaluated by spectrophotometric analysis in the ultraviolet visible region. The study showed that the morphology of the membranes has a great influence on the desorption of the drugs and that the release occurs predominantly by diffusion.
Beyond spectrophotometric technique, voltammetry has been cited in the literature for drugs quantitation ${ }^{20-37}$, which have electroactive groups that can be detected voltametricamente ${ }^{7}$. We recently have demonstrated that SWV is a very attractive analytical technique for studying naproxen controlled releasing from cellulosic materials. This technique is especially useful to real-time monitoring of the fast initial release stages, which cannot be accessed by analytical techniques usually employed in controlled drug releasing studies, such as spectrophotometry or chromatography. In addition, SWV can be successfully used to follow naproxen releasing profiles from cellulosic microparticles, which is difficult by spectrophotometry in the UV region. ${ }^{7}$

In this work, cellulose acetate produced from sugarcane bagasse was used in the production of membranes as matrices for the incorporation of paracetamol. The study of drug release from the polymer matrix was made by SWV, which is a fast and accurate electroanalytical technique that is able to monitor paracetamol in real time once the electrochemical sensor is placed inside the subject of the drug release experiment. SWV presents several advantages over the traditional ultraviolet visible spectrophotometry technique, including higher sensitivity and selectivity, wider linear concentration range, and no need for sample collection (in situ monitoring). ${ }^{20}$

\section{Experimental \\ Purification of sugarcane bagasse and production of cellulose triacetate}

Sugarcane bagasse was delignified and further acetylated according to the methodology described. Delignified bagasse is composed of

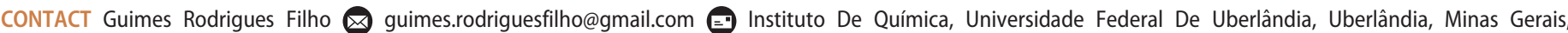
38400-902, Brazil 
87.59\% cellulose, $12.00 \%$ hemicellulose and $0.41 \%$ lignin. The produced cellulose acetate presents a degree of substitution of $2.80 \pm 0.09$ and is classified as cellulose triacetate and a viscosity average molecular weight of $39000 \mathrm{~g} \mathrm{~mol}^{-1}$, as previously reported. ${ }^{6}$

\section{Membrane production and paracetamol incorporation}

The casting solution was prepared by dissolving CTA $(10.0 \%$ $\mathrm{w} / \mathrm{w})$ and paracetamol $(5.0 \% \mathrm{~m} / \mathrm{m})$ in dichloromethane (MB-SYMpara). For the asymmetric membrane, the same formulation was utilized, and $10 \%$ water was added as a pore-forming agent (MB-ASYpara).

\section{Scanning electron microscopy}

Scanning electron microscopy (SEM) was used to analyze the membrane surfaces and cross sections. In order to obtain cross sections, the membranes were fractured in liquid nitrogen. The samples were gold coated, and then, micrographs were obtained in a Carl Zeiss, EVO MA 10 scanning electron microscope, (Oberkochen, Germany) operating at $10 \mathrm{kV}$.

\section{Differential scanning calorimetry}

Differential scanning calorimetry (DSC) measurements were carried out in a TA Q-20 equipment (New Castle, DE) at $10^{\circ} \mathrm{C} \mathrm{min}^{-1}$, using a nitrogen inert atmosphere at $50 \mathrm{~cm}^{3} \mathrm{~min}^{-1}$. The scan first was carried out from $20^{\circ} \mathrm{C}$ up to $350^{\circ} \mathrm{C}$. In second scan, the samples were heated to $250^{\circ} \mathrm{C}$ and immediately cooled to $70^{\circ} \mathrm{C}$ and heated again up to $280^{\circ} \mathrm{C}$, in order to determine the glass transition $\left(T_{\mathrm{g}}\right)$ of the polymer.

\section{Study of paracetamol release from cellulose triacetate membranes by square-wave voltammetry}

In the evaluation of drug release, a thermostatic bath was used in order to ensure that the temperature of the experiment was maintained about $36.5^{\circ} \mathrm{C}$, and phosphate buffer solution ( $\mathrm{pH} 7.4$ ) was used ${ }^{6}$. Drug release was monitored in the solution from a Type III $\mu$ Autolab potentiost at connected to a microcomputer. For controlling the equipment, GPES software, (Low Countries, Netherlands) version 4.9, was used. The drug-release measurements were obtained using square-wave voltammetry.

The microcell consisted of a 50-mL beaker, a platinum wire as a counter electrode, a glassy carbon disc electrode $(2 \mathrm{~mm}$ diameter) as the working electrode and a miniaturized $\mathrm{Ag} / \mathrm{AgCl}$ (sat. $\mathrm{KCl}$ ) electrode built on a micropipette tip as a reference electrode ${ }^{20}$.

The glassy carbon-working electrode was polished in alumina suspension and then washed with deionized water. For the analysis procedure, $25 \mathrm{~mL}$ of a phosphate buffer solution preheated to $36.5^{\circ} \mathrm{C}$ and a portion of the membrane containing the incorporated drug was introduced into the micro cell. Next, the three electrode system was introduced and held the first voltammogram $(t=0)$. From this voltammogram, others were performed every $20 \mathrm{~min}$. All voltammograms were made using the following conditions: initial $=0.0 \mathrm{~V}$; final $=1.00 \mathrm{~V}$; step potential $=0.01995 \mathrm{~V} ; \quad$ amplitude $=0.04995 \mathrm{~V} ; \quad$ frequency $=20 \mathrm{~Hz}$; scan rate $=0.399 \mathrm{Vs}^{-1}$.

\section{Results and discussion}

Membrane characterization

\section{SEM study}

The membrane morphology, which plays a key role in the drug release kinetics, can be studied by SEM. Figure 1 shows the results for cross section and surface structures.

The results show that symmetric membranes form dense structures, aspect observed both on the surface, as in the fracture. In these membranes, structures without pores and the presence of areas with uniformity and a high density of polymer could be seen. With the addition of paracetamol, the membrane had practically the same morphology.

In the asymmetric membranes, which are produced with water as a nonsolvent, pores on the surface and throughout their thickness could be seen. The pores were of nonuniform size and were distributed irregularly along the membrane.

These morphological differences are directly related to the processing used. During the membrane formation from solution (CTA/dichloromethane/water), the solvent (dichloromethane) and nonsolvent (water) evaporate at different rates. The solvent evaporates faster than the water, causing two effects: an increase in the time of coalescence of the membrane, leading to phase separation and increased water concentration in the polymer structure, causing pore formation.

The addition of paracetamol to the formulation causes a reduction in the number of pores formed on the surface and in cross section. The water typically causes a destabilization in the system and consequently, the phase separation. The drug interacts with both the membrane and the water and hence reduces the intensity of phase separation, which occurs in a smaller proportion.

\section{DSC study}

One fundamental aspect on the employment of thermal analysis when evaluating matrices for drug controlled-release is the fact that this method permits the investigation of thermal stability of both matrix and drug, as well as the nature of dispersion of the drug in the matrix 6 . An important parameter to study the interaction between paracetamol and polymer is the glass transition temperature $\left(T_{\mathrm{g}}\right)$, which is obtained from the second scan DSC curves. Figure 2 shows the first and second scan DSC curve of all membranes.

Figure 2(A) and (B) present DSC curves of first scan for cellulose triacetate symmetric and asymmetric membranes with and without the incorporation of paracetamol. The thermograms presented are typical of cellulose triacetate, in which an endotherm between $60^{\circ} \mathrm{C}$ and $100^{\circ} \mathrm{C}$ may be observed, along with the desorption of water associated with the polymer structure. An exothermic peak at approximately $192^{\circ} \mathrm{C}$ relative to the crystallization of the polymer during the scan, and an endotherm at approximately $300^{\circ} \mathrm{C}$ due to CTA fusion ${ }^{6}$.

The data of Figure 2(B) and (C) show that the glass transition temperature decreased with the addition of paracetamol in membranes. The drug molecules, which are usually small, are retained between the polymer chains. This reduces the intermolecular forces of attraction between the polymer molecules, thus increasing mobility of the chains, which results in a reduction in the $T_{\mathrm{g}}$ value $^{38}$.

In asymmetric membrane, the paracetamol caused a decrease in the value of $T_{\mathrm{g}}$ of $33^{\circ} \mathrm{C}$, while in the symmetric membrane, the reduction was less significant $\left(6.5^{\circ} \mathrm{C}\right)$. This difference in values shows that the interaction between the membrane and paracetamol is more pronounced with MB-ASYpara. The drug has a plasticizing 
(A)

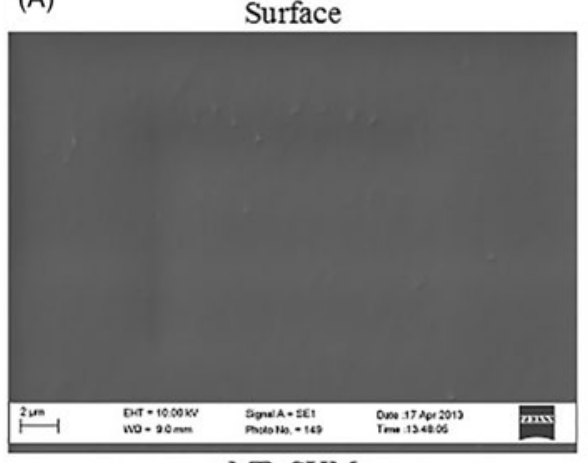

MB-SYM

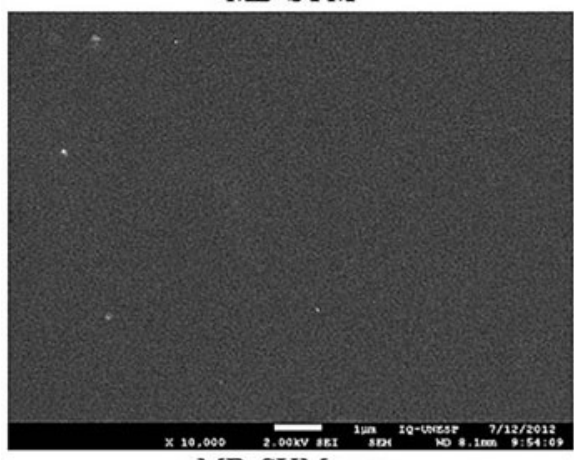

MB-SYMpara

(B)

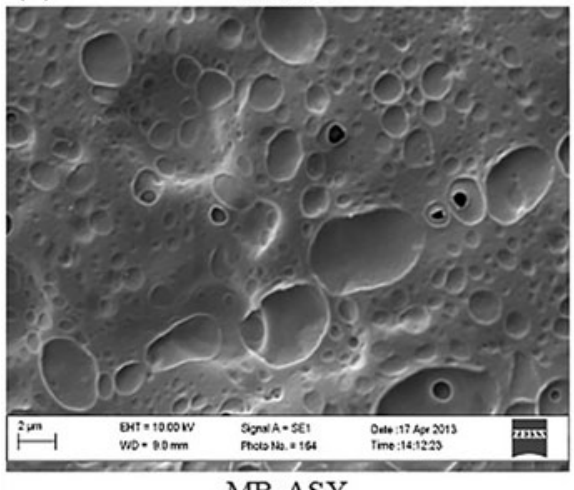

MB-ASY

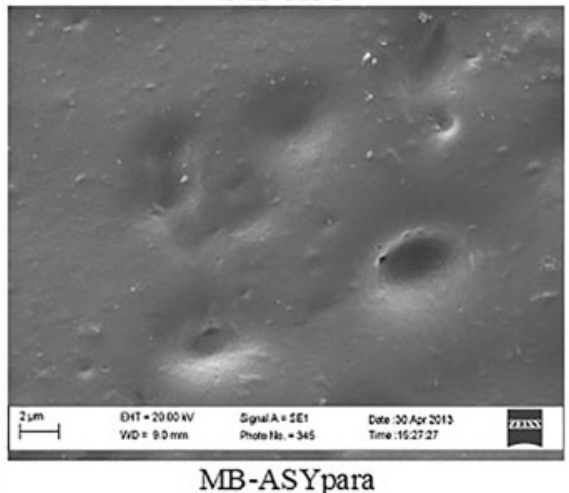

Cross-section

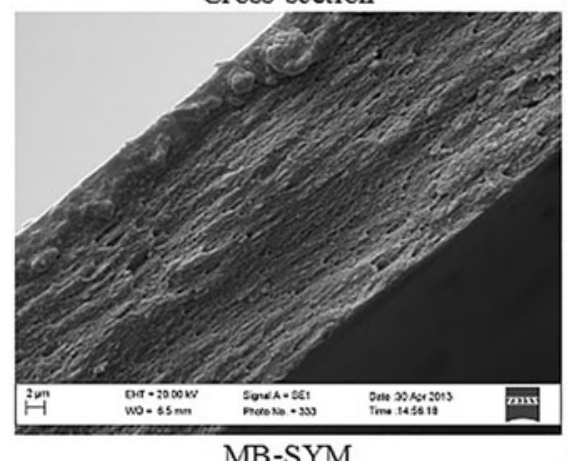

MB-SYM

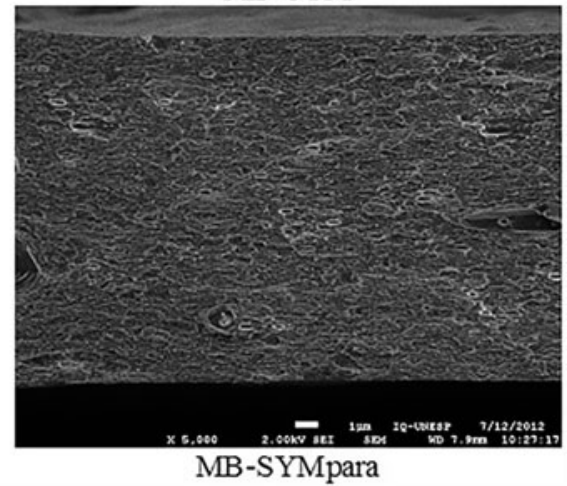

Cross-section
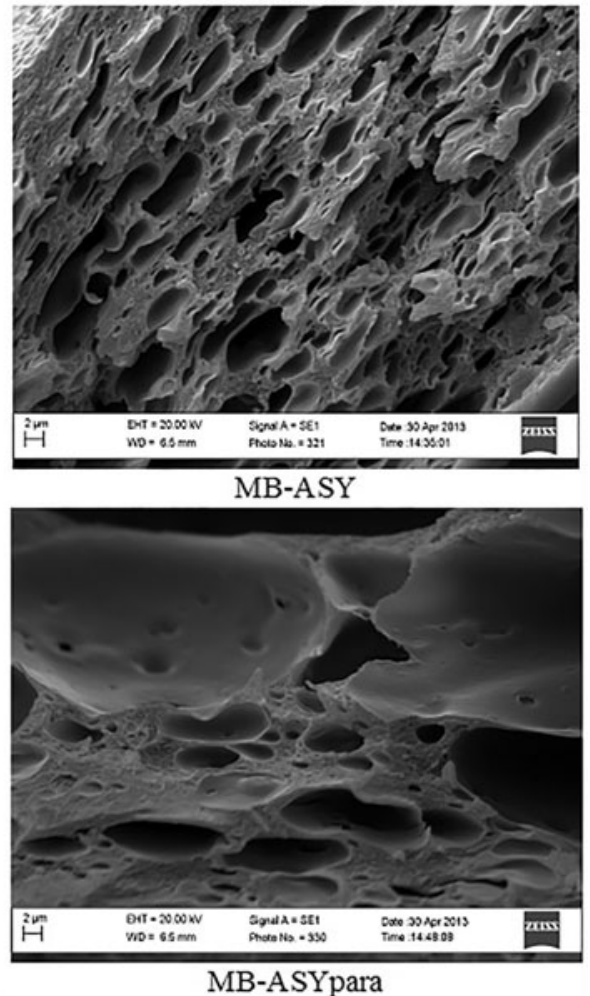

Figure 1. SEM of the fracture and surface, symmetric membranes (A) without drug (MB-SYM) and with drug (MB-SYMpara); asymmetric (B) without drug (MB-ASY) and with drug (MB-ASYpara). 

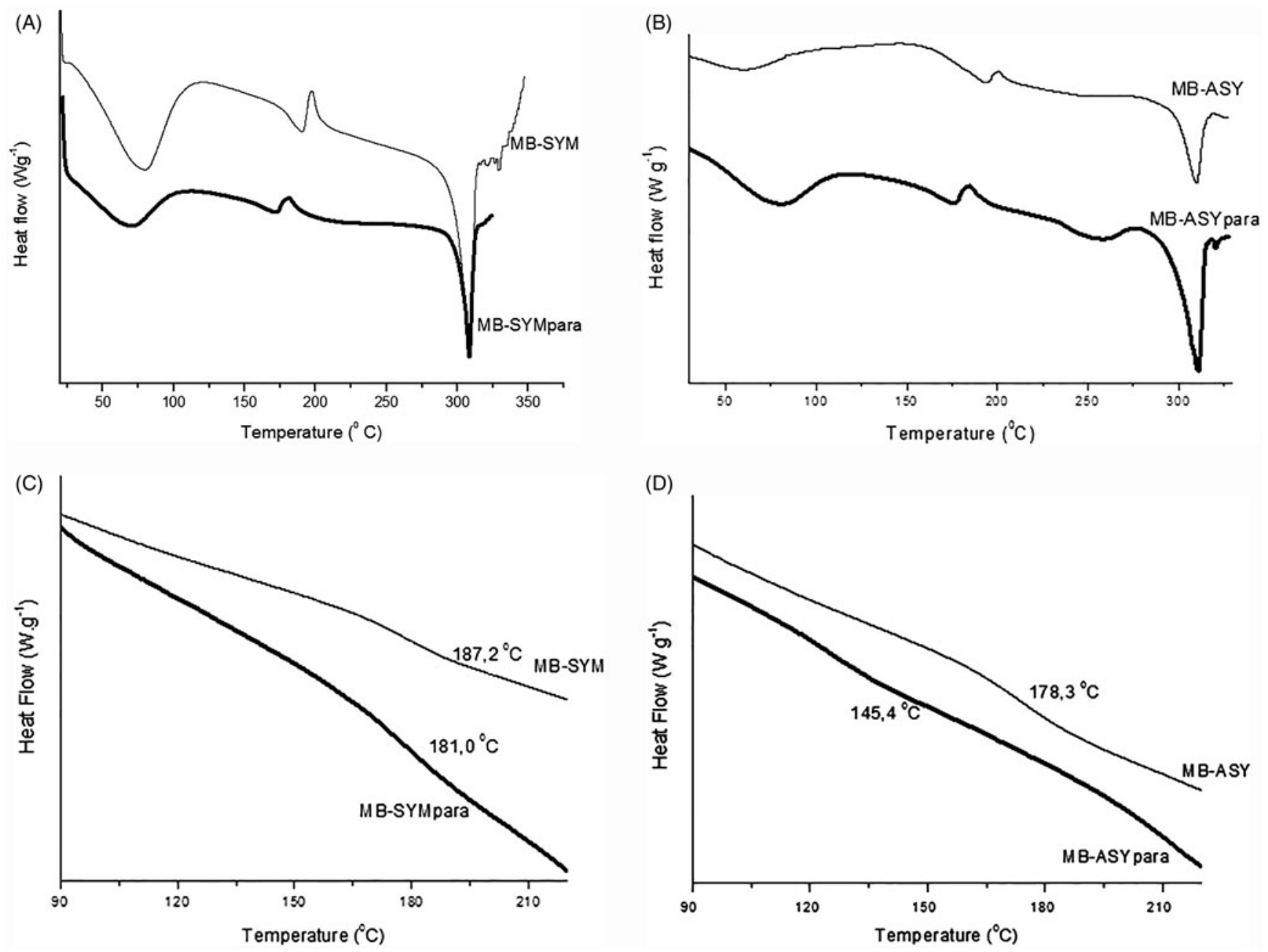

Figure 2. First and second scan DSC curves. Symmetric membranes ( $A$ and $C$ ), asymmetric membranes (B and D).

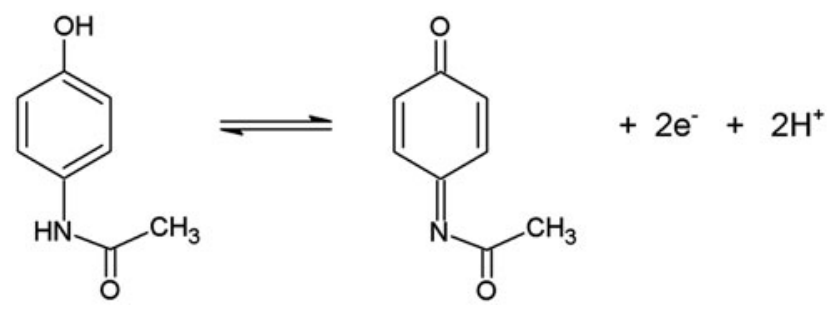

Figure 3. Mechanism of the electrochemical oxidation of paracetamol.

effect on the system. These results are in agreement with those of SEM both the surface and substructure of the membrane.

\section{Monitoring of paracetamol release by square-wave voltammetry}

Paracetamol is a phenolic compound that undergoes electrochemical oxidation by electrolytic etching on the aromatic ring with irreversible removal of two electrons and two protons, producing $\mathrm{N}$-acetyl-p-quinoneimine according to the mechanism shown in Figure 3.

The monitoring of released paracetamol content was made using the SWV technique. Initially, a calibration curve was carried out, in which equal amounts of a stock solution of $10 \mathrm{mM}$ paracetamol were added to a buffer solution under the same conditions in which the analysis of drug release was made. By measuring the height of the peaks formed (current responses) at the different concentrations of added paracetamol, a highly linear $\left(R^{2}=0.9989\right)$ calibration curve (in the range of 5 to $100 \mu \mathrm{molL}^{-1}$ ) was obtained with the following equation: $I(\mu \mathrm{A})=0.035+0.1154 x$ [Paracetamol] $\left(\mu \mathrm{mol} \mathrm{L}^{-1}\right)$. This calibration curve was used to calculate the amount of paracetamol released from the membranes and then converted into percentage of drug release. Figure 4 shows voltammograms obtained with symmetric and asymmetric membranes.

Shift of the oxidation potential of paracetamol is observed in both experiments of drug release presented in Figure 4. Repetitive voltammograms for the standard solutions of paracetamol in $0.1 \mathrm{~mol} / \mathrm{L}$ phosphate buffer $\mathrm{pH} 7.5$ showed a similar displacement of the oxidation peak of paracetamol. Therefore, the shift of oxidation potential may be due to partial passivation of the electrode surface related to the adsorption of paracetamol or its oxidation product. However, this potential shift did not affect the linear range of the voltammetric determination of paracetamol. Therefore, the equation for the calibration curve obtained before drug release experiment can be used to determine the content of paracetamol in solution. The drug release experiment was performed in a medium that simulates the biological conditions of paracetamol absorption in human body $(0.1 \mathrm{~mol} / \mathrm{L}$ phosphate buffer $\mathrm{pH}$ 7.5). 
(A)

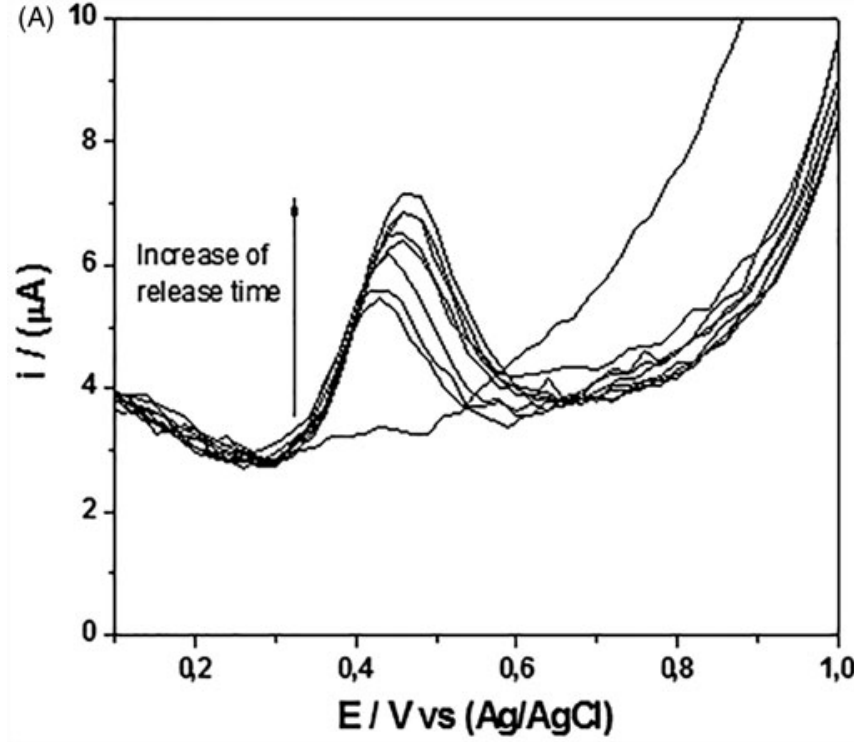

(B)

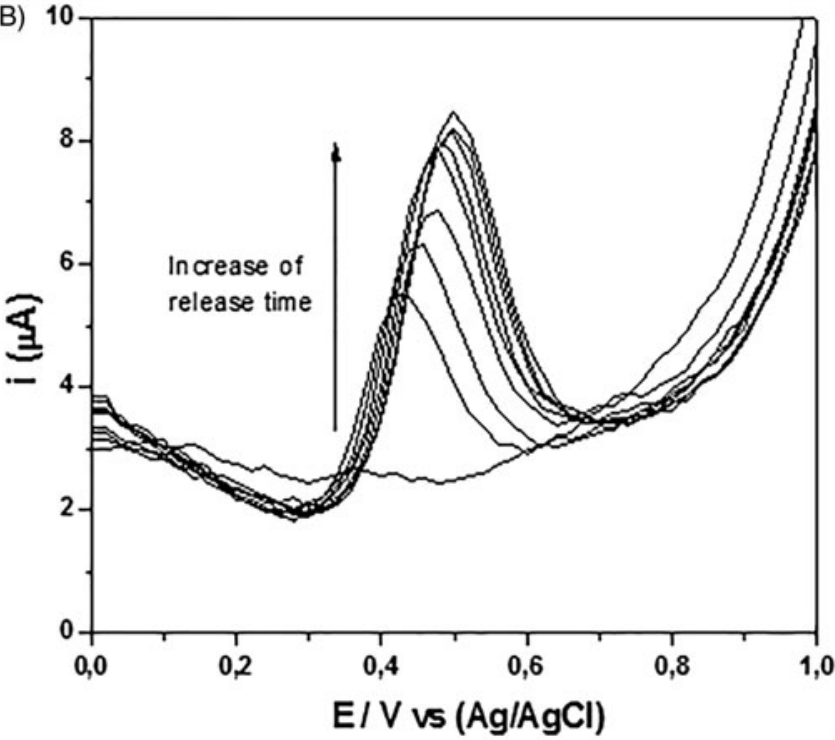

Figure 4. Voltammograms obtained from the paracetamol released from symmetric (A) and asymmetric (B) membranes.
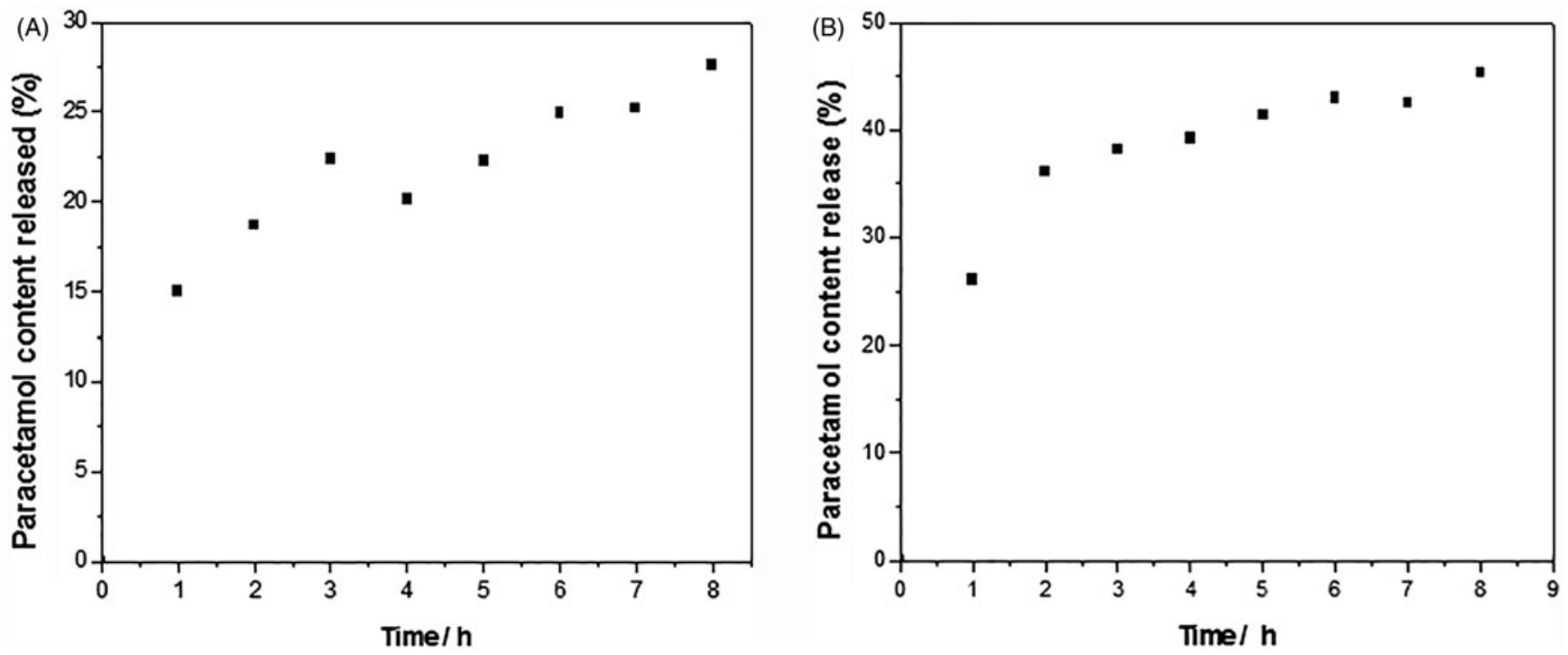

Figure 5. Curves of paracetamol released from symmetric (A) and asymmetric (B) membranes.

The analysis of the voltammograms reveals that the drug release occurs differently on each membrane, since the peak height formed is directly proportional to the concentration of analyte in the solution. Obtaining the height of the peaks and using the equation of the calibration curve, it was possible to determine the concentration of paracetamol released from the membranes (Figure 5).

The paracetamol is soluble in water, and the release occurs as the solution comes into contact with the polymer system, resulting in relaxation of the polymer chains with volume expansion, which facilitates the diffusion of the drug through the matrix. The values of paracetamol release versus time indicate the influence of the membrane structure in the release of the drug.

Confirming the data from the voltammograms, with the asymmetric membrane, a large amount of drug that was incorporated into the matrix was released, reaching approximately $45 \%$ of the paracetamol at around $8 \mathrm{~h}$ of the experiment. This differs from that observed in the symmetric membrane, where only $27 \%$ of the drug was released.
An aspect that accounts for the difference in the percentage of released drug by each membrane is the existence of pores in the asymmetric membrane. The pores on the surface and throughout the thickness of the membrane control the transfer and facilitate the movement of the drug across the membrane. When the pores are achieved, they do not offer resistance to the paracetamol flow.

Paracetamol has a plasticizing effect on the system, as demonstrated by DSC studies, resulting in increased mobility of the polymer chains. This increase in mobility favors the transport of the drug across the membrane and its subsequent release.

The tests showed that it is possible to use square-wave voltammetry in the study of controlled drug release systems. Its main advantages over the spectrophotometric technique include: in situ monitoring, making it unnecessary to handle samples for reading, thus avoiding temperature loss, and there is less chance of contamination by other materials; easy system handling and low cost of operation; rapid stabilization of the apparatus; analysis in a short time; the dispensability of dilutions for sample reading (wide 
linear range, from 5 to $100 \mu \mathrm{molL}^{-1}$ ), high sensitivity and reduced spending of reagent and sample.

\section{Conclusion}

The SEM results indicated the formation of a symmetric (MB-SYM) and asymmetric (MB-ASY) membrane. The paracetamol incorporation in membranes was confirmed by the changes in the thermal properties of the matrix with a reduction in the value of the $T_{\mathrm{g}}$ in the presence of the drug, showing a strong interaction with the polymer matrix in the case of asymmetric membranes. Quantitative analysis of drug release using square-wave voltammetry showed that $27 \%$ and $45 \%$ of the drug was released from symmetric and asymmetric membranes, respectively, after $8 \mathrm{~h}$ of analysis. The results show that the membranes produced from the use of sugarcane bagasse have potential for application in controlled release of paracetamol. Additionally, square-wave voltammetry is an important technique in studies of drug release for these systems, especially when in situ and real time monitoring is required.

\section{Acknowledgments}

The authors thank CAPES for the access to "Portal Perió dicos", to FAPEMIG for project CEX-APQ-01128/13 and to Faculdade de Engenharia Quimica of the Federal University of Uberlandia for the use of the SEM. Ribeiro and Tormin thank CAPES and FAPEMIG for the scholarships, respectively.

\section{Declaration of interest}

The authors report no declarations of interest.

\section{References}

1. Villanova JCO, Oréfice RL, Cunha AS. Aplicações farmacêuticas de polímeros. Polímeros: ciênc Tecnol 2010;20:51-64.

2. Lopes CM, Lobo JMS, Costa P. Formas farmacêuticas de liberação modificada: polímeros hidrifílicos. Rev Bras Cienc Farm 2005;41:143-54.

3. Ma D, McHugh AJ. The interplay of phase inversion and membrane formation in the drug release characteristics of a membrane-based delivery system. J Membr Sci 2007;298:156-68.

4. Garg A, Gupta M, Bhargava HN. Effect of formulation parameters on the release characteristics of propranolol from asymmetric membrane coated tablets. Eur J Pharm Biopharm 2007;67:725-31.

5. Thombre AG, Zentner GM, Himmelstein KJ. Mechanism of water transport in controlled porosity osmotic devices. J Membr Sci 1989;40:279-310.

6. Filho GR, Ribeiro SD, Meireles CS, et al. Release of doxycycline through cellulose acetate symmetric and asymmetric membranes produced from recycled agroindustrial residue: sugarcane bagasse. Ind Crop Prod 2011;33:566-71.

7. Fonseca WT, Santos RF, Montes RHO, et al. Square wave voltammetry as analytical tool for real-time study of controlled naproxen releasing from cellulose derivative materials. Electroanalysis 2015; 27:1847-1854

8. Meier MM, Kanis LA, Soldi V. Characterization and drugpermeation profiles of microporous and dense cellulose acetate membranes: influence of plasticizer and pore forming agent. Int J Pharm 2004;278:99-110.

9. Castillo-Ortega MM, Nájera-Luna A, Rodriguez-Félix DE, et al. Preparation, characterization and release of amoxicillin from cellulose acetate and poly (vinyl pyrrolidone) coaxial electrospun fibrous membranes. Mater Sci Eng C 2011;31:1772-8.

10. Castillo-Ortega MM, Montaño-Figueroa AG, Rodriguez-Félix $\mathrm{DE}$, et al. Amoxicillin embedded in cellulose acetatepoly (vinyl pyrrolidone) fibers prepared by coaxial electrospinning: preparation and characterization. Mater Lett 2012;76:250-4.

11. Ende MT, Miller LA. Mechanistic investigation of drug release from asymmetric membrane tablets: effect of media gradients (osmotic pressure and concentration), and potential coating failures on in vitro release. Pharm Res 2007;24:288-97.

12. Makhija SN, Vavia PR. Controlled porosity osmotic pump-based controlled release systems of pseudoephedrine. I. Cellulose acetate as a semipermeable membrane. J Control Release 2003;89:5-18.

13. Tungprapa S, Jangchud I, Supaphol P. Release characteristics of four model drugs from drug-loaded electrospun cellulose acetate fiber mats. Polymer 2007;48:5030-41.

14. Waterman KC, Goeken GS, Konagurthu S, et al. Osmotic capsules: a universal oral, controlled-release drug delivery dosage form. J Control Release 2011;152:264-9.

15. $\mathrm{Xu} \mathrm{L,} \mathrm{Li} \mathrm{S,} \mathrm{Sunada} \mathrm{H.} \mathrm{Preparation} \mathrm{and} \mathrm{evaluation} \mathrm{in} \mathrm{vitro} \mathrm{and}$ in vivo of captopril elementary osmotic pump tablets. Asian J Pharm Sci 2006;1:236-45.

16. Madaeni SS, Derakhshandeh K, Ahmadi S, et al. Effect of modified multi-walled carbon nanotubes on release characteristics of indomethacin from symmetric membrane coated tablets. J Membr Sci 2012;389:110-16.

17. Ruggiero R, Carvalho VA, Silva LG, et al. Study in vitro degradation of cellulose acetate membranes modified and incorporated with tetracycline for use as an adjuvant in periodontal reconstitution. Ind Crop Prod 2015;72:2-6.

18. Olejnik A, Nowak I. Atomic force microscopy analysis of synthetic membranes applied in release studies. Appl Surf Sci 2015; 10:128-37

19. Li G, Wang $Y$, Chen $H$, et al. Can semipermeable membranes coating materials influence in vivo performance for paliperidone tri-layer ascending release osmotic pump tablet: in vitro evaluation and in vivo pharmacokinetics study. Asian J Pharm Sci 2015;10:128-37.

20. Mora L, Chumbimuni-Torres KY, Clawson C, et al. Real-time electrochemical monitoring of drug release from therapeutic nanoparticles. J Control Release 2009;140:69-73.

21. Ardila JA, Oliveira GG, Medeiros RA, Fatibello-Filho $O$. Determination of gemfibrozil in pharmaceutical and urine samples by square-wave absorptive stripping voltammetry using a glassy carbon electrode modified with multi-walled carbon nanotubes within a dihexadecyl hydrogen phosphate film. J Electroanal Chem 2013;690:32-7.

22. Braga OC, Campestrini I, Vieira IC, Spinelli VA. Sulfadiazine determination in pharmaceuticals by electrochemical reduction on a glassy carbon electrode. J Braz Chem Soc 2010;21:813-20.

23. El-Maali NA. Voltammetric analysis of drugs. Bioelectrochem 2004;64:99-107.

24. Elqudaby HM, Mohamed GG, Ali FA, Eid SM. Validated voltammetric method for the determination of some antiprotozoa drugs based on the reduction 
at an activated glassy carbon electrode. A J Chem 2013;6:327-33.

25. Elqudaby HM, Mohamed GG, El Din GMG. Electrochemical behavior of trimebutine at activated glassy carbon electrode and its direct determination in urine and pharmaceutics by square wave and differential pulse voltammetry. Int J Electrochem Sci 2014;9:856-69.

26. El-Shal MA. Electrochemical studies for the determination of quetiapine fumarate and olanzapine antipsychotic drugs. Adv Pharm Bull 2013;3:339-44.

27. Gholivand MB, Khodadadian M. Simultaneous voltammetric determination of theophylline and guaifenesin using a multiwalled carbon nanotube-ionic liquid modified glassy carbon electrode. Electroanal 2014;26:1975-83.

28. Gupta VK, Jain R, Radhapyari K, et al. Voltammetric techniques for the assay of pharmaceuticals-a review. Anal Biochem 2011;408:179-96.

29. Jain R, Sharma R. Novel bismuth/multi-walled carbon nanotubes-based electrochemical sensor for the determination of neuroprotective drug cilostazol. J Appl Electrochem 2012;41:341-8.

30. Oliveira GG, Janegitz BC, Zucolotto V, Fatibello-Filho O. Differential pulse adsorptive stripping voltammetric determination of methotrexate using a functionalized carbon nanotubes - modified glassy carbon electrode. Cent Eur J Chem 2013;11:1837-43.
31. Robinson DL, Venton BJ, Henin MLAV, Wightman RM. Detecting subsecond dopamine release with fast-scan cyclic voltammetry in vivo. Clin Chem 2003;49:1763-73.

32. Santos AL, Takeuchi RM, Stradiotto NR. Electrochemical, spectrophotometric and liquid - chromatographic approaches for analysis of tropical disease drugs. Curr Pharm Anal 2009;5:69-88.

33. Zaied SIM, Arida HAM. Voltammetric determination of the cough suppressant drug dropropizine in its pharmaceutical formulations and human urine. Int J Electrochem Sci 2015;10:3250-9.

34. Sirivisoot S, Pareta R, Webster TJ. Electrically controlled drug release from nanostructured polypyrrole coated on titanium. Nanotechnology 2011;22:1-15.

35. Sun M, Kaplan SV, Gehringer RC, et al. Localized drug application and sub-second voltammetric dopamine release measurements in a brain slice perfusion device. Anal Chem 2014;86:4151-6.

36. Zare MA, Tehrani MS, Husain SW, Azar PA. Multiwall carbon nanotube-ionic liquid modified paste electrode as an efficient sensor for the determination of diazepam and oxazepam in real samples. Electroanalysis 2014;26:2599-606.

37. Pedrotti JJ, Angnes L, Gutz IGR. Miniaturized reference electrodes with microporous polymer junctions. Electroanalysis 1996;86:673-5.

38. Souza PP, Silva GG, Amaral LOF. O Cotidiano é meio amorfo: transição vítrea uma abordagem para o ensino médio. Quím Nova Esc 2004;20:21-5. 